\title{
The Novelty of the 2015 Guidelines of the Taiwan Society of Cardiology and the Taiwan Hypertension Society for the Management of Hypertension
}

\author{
Hao-Min Cheng ${ }^{a, b} \quad$ Chern-En Chiang ${ }^{b-d} \quad$ Chen-Huan Chen ${ }^{a-c}$ \\ ${ }^{a}$ Department of Medical Education, Taipei Veterans General Hospital, and ${ }^{b}$ Department of \\ Medicine, 'Cardiovascular Research Center, National Yang-Ming University, and \\ ${ }^{d}$ General Clinical Research Center, Taipei Veterans General Hospital, Taipei, Taiwan, ROC
}

\section{Key Words}

Guidelines · Hypertension · High blood pressure

\begin{abstract}
The prevalence rate of hypertension in Asian countries grows faster than in other parts of the world, where stroke exceeds coronary heart disease in causing morbidities and mortalities. The optimal management of hypertension is therefore an especially important task in Asia. In a transparent and rigorous guideline development process, the most updated information available on the management of hypertension was summarized in the 2015 Taiwan Society of Cardiology (TSOC)/Taiwan Hypertension Society (TSH) hypertension guideline. In contradiction with the ESH/ESH joint hypertension guidelines and the 2014 Joint National Committee (JNC) report, this updated guideline suggests some different blood pressure (BP) targets. In brief, the BP target is $150 / 90 \mathrm{~mm} \mathrm{Hg}$ for very elderly patients ( $\geq 80$ years), $130 / 80 \mathrm{~mm} \mathrm{Hg}$ for patients with diabetes, coronary heart disease, proteinuric chronic kidney disease or those receiving antithrombotics for stroke prevention, and $140 / 90 \mathrm{~mm} \mathrm{Hg}$ for all the other hypertension patients with or without the aforementioned comorbidities. To facilitate the adherence to the guideline, the following was proposed: mnemonics for lifestyle modifications: S$A B C D E$ (Sodium restriction, Alcohol limitation, Body weight reduction, Cigarette smoking cessation, Diet adaptation, and Exercise adoption), treatment algorithm: PROCEED (Previous experience, Risk factors, Organ damage, Contraindications or unfavorable conditions, Expert's or doctor's judgment, Expenses or cost, and Delivery and compliance issue), and medication adjustment algorithm: AT GOALs (Adherence, Timing of administration, Greater doses, Other
\end{abstract}


Cheng et al.: The Novelty of the 2015 Guidelines of the Taiwan Society of Cardiology and the Taiwan Hypertension Society for the Management of Hypertension

classes of drugs, Alternative combination or single-pill combination, and Lifestyle modification + Laboratory tests). In particular, the effort of translating the concept of central BP into clinical practice may stand out from all other hypertension guidelines. In summary, our guidelines may deliver useful information and guidance to clinicians in managing hypertensive patients, including the approach to a more accurate diagnosis, treatment and adjustment algorithm, and evidence-based recommendations.

(c) 2015 S. Karger AG, Base

\section{Brief Summary of the TSOC/THS 2015 Hypertension Guideline}

Following the 2010 Taiwan Society of Cardiology (TSOC) guideline for the management of hypertension [1], the executive committee of the Taiwan Society of Cardiology and the Taiwan Hypertension Society (THS), based on new data from clinical trials, post hoc analyses, meta-analyses, and guidelines from other international societies [2, 3], decided to publish an updated 2015 hypertension guideline to provide clinicians with up-to-date evidence-based practice guidance for the management of hypertension [4]. In contrast to the 2010 guideline and guidelines issued by other societies, the new and unique aspects of this updated version of the Taiwan hypertension guideline are presented in this brief review.

\section{The Prevalence and Control Rate of Hypertension in Taiwan}

In the 2002 Taiwanese Survey on Hypertension, Hyperglycemia, and Hyperlipidemia (TwSHHH), the nationwide prevalence rates of hypertension [defined by systolic blood pressure (BP) $140 \mathrm{~mm} \mathrm{Hg}$ or diastolic BP $90 \mathrm{~mm} \mathrm{Hg}$ ] were 25\% in men and 18\% in women, and that rate increased to $47 \%$ among individuals aged 60 years [5]. However, the control rate in patients aged 19 years was only $21.0 \%$ in men and $28.5 \%$ in women [5]. Since the implementation of the National Health Insurance system in 1995, the control rate of hypertension has improved to as high as approximately $50 \%$ for women in the northern Taiwan [1].

It has been well recognized that the death rate attributable to stroke is higher than that due to coronary heart disease (CHD) in eastern Asia [6]. Considering the finding that hypertension is the most important risk factor for stroke [7], and the impact of hypertension on stroke and CHD is higher in Asians than Caucasians [8], the importance of optimal management for hypertension in Asian countries to prevent cardiovascular disease, especially stroke, could not be overemphasized, and therefore an updated local hypertension guideline is urgently needed.

\section{Comparison with Guidelines of Other Societies}

In order to maintain the transparency of the developmental process of the present guideline, all the discussions and presentations within the consensus meetings were recorded and can be freely accessed online (TSOC APP). To achieve a better clarity of the guideline suggestions, similar methodologies to those developed by the American College of Cardiology (ACC) and the American Heart Association (AHA) were adopted, and all suggestions are presented with the corresponding class of recommendation (COR) and level of evidence (LOE). 
Cheng et al.: The Novelty of the 2015 Guidelines of the Taiwan Society of Cardiology and the Taiwan Hypertension Society for the Management of Hypertension

Table 1. Comparison of the 2013 ESH/ESC hypertension guidelines, the 2014 JNC report, and the 2015 TSOC/THS hypertension guideline

\begin{tabular}{|c|c|c|c|}
\hline & $2013 \mathrm{ESH} / \mathrm{ESC}$ & 2014 JNC report & 2015 TSOC/THS \\
\hline Diagnosis flow chart & - & - & + \\
\hline Treatment flow chart & - & + & + \\
\hline Lifestyle modification & + & - & + \\
\hline \multirow[t]{2}{*}{$\mathrm{BP}$} & + & + & + \\
\hline & $\begin{array}{l}\text { Universally } \\
<140 / 90 \mathrm{~mm} \mathrm{Hg}\end{array}$ & $\begin{array}{l}<140 / 90 \mathrm{~mm} \mathrm{Hg} \\
(<150 / 90 \text { for age }>60)\end{array}$ & $\begin{array}{l}<140 / 90 \mathrm{~mm} \mathrm{Hg} \\
(\text { or }<130 / 80 \text { for special } \\
\text { patient groups }^{\text {a }} \text { ) }\end{array}$ \\
\hline Treatment in special conditions & + & - & + \\
\hline Treatment of associated risk factors & + & - & - \\
\hline \multicolumn{4}{|l|}{ Standards of IOM } \\
\hline Transparency & ? & $?$ & $+^{\mathrm{b}}$ \\
\hline Conflict of interests & Full disclosure & Full disclosure & Full disclosure \\
\hline Group compositions (advisory board members) & $\mathrm{n}=55$ & $\mathrm{n}=51$ & $\mathrm{n}=53$ \\
\hline Systemic review & $+^{\mathrm{c}}$ & $+t^{\mathrm{d}}$ & $+^{\mathrm{e}}$ \\
\hline Strength of recommendation & + & + & + \\
\hline Articulation & + & $?$ & + \\
\hline External review & + & + & + \\
\hline Updating & + & + & + \\
\hline Appropriateness for Asians & $?$ & $?$ & + \\
\hline
\end{tabular}

Adapted from the 2015 TSOC/TSH hypertension guideline [4] with permission. ESC = European Society of Cardiology; ESH = European Society of Hypertension; IOM = Institute of Medicine.

a Patients with diabetes, CHD or proteinuric chronic kidney disease. ${ }^{\mathrm{b}}$ All presentations can be viewed online (http://tw.i519. org/tsoc). ${ }^{\mathrm{c}}$ Randomized controlled trials, meta-analyses, and cohort studies. ${ }^{\mathrm{d}}$ Only randomized controlled trials. ${ }^{\mathrm{e}}$ Randomized controlled trials, meta-analyses, nonrandomized trials, subgroup analyses, post hoc analyses, retrospective studies, cohort studies, registration studies, and small studies, especially focused on available data for Asians.

Table 1 summarizes the similarities and differences between the 2013 ESH/ESC hypertension guidelines [3], the 2014 Joint National Committee (JNC) report [2], and the 2015 TSOC/TSH hypertension guideline [4]. BP targets are the major differences among these guidelines, with details provided in table 2 . In brief, the BP target is $150 / 90 \mathrm{~mm} \mathrm{Hg}$ for very elderly patients ( $\geq 80$ years), $130 / 80 \mathrm{~mm} \mathrm{Hg}$ for patients with diabetes, CHD, proteinuric chronic kidney disease, or those receiving antithrombotics for stroke prevention, and 140/90 mm Hg for all the other hypertension patients with aforementioned conditions. Evidence supporting such recommendations was provided in detail throughout the guideline [4].

\section{What Is New in the 2015 TSOC/THS Hypertension Guideline?}

With evidence revolution, the 2015 hypertension guideline makes some changes in some recommendations and gives additional suggestions in comparison with the 2010 guidelines (table 3). The new guideline provides a correct BP measurement process and a diagnostic algorithm that highlights the importance of home BP monitoring and ambulatory BP monitoring. It also modifies the suggestions for lifestyle modification, which could be easily associated with by the mnemonics (S-ABCDE: Sodium restriction, Alcohol limitation, Body weight reduction, Cigarette smoking cessation, Diet adaptation, and Exercise adoption). Moreover, 
Cheng et al.: The Novelty of the 2015 Guidelines of the Taiwan Society of Cardiology and the Taiwan Hypertension Society for the Management of Hypertension

Table 2. BP targets

\begin{tabular}{llll}
\hline Categories & BP targets, mm Hg & COR & LOE \\
\hline Primary prevention & $<140 / 90$ & IIa & B \\
Secondary prevention & & & \\
$\quad$ Diabetes & $<130 / 80$ & I & B \\
$\quad$ CHD & $<130 / 80$ & I & B \\
$\quad$ Stroke & $<140 / 90$ & I & A \\
$\quad$ CKD & $<140 / 90$ & I & A \\
$\quad$ CKD with proteinuria & $<130 / 80$ & IIb & IIa \\
Very elderly patients (age $\geq 80$ years) & $<150 / 90$ & I & B \\
Patients receiving antithrombotics for stroke prevention & $<130 / 80$ & & \\
\hline
\end{tabular}

Adapted from the 2015 TSOC/TSH hypertension guideline [4] with permission. CKD = Chronic kidney disease.

Table 3. Comparison of the 2010 TSOC hypertension guidelines and the 2015 TSOC/THS hypertension guideline

\begin{tabular}{|c|c|c|}
\hline & 2010 TSOC & 2015 TSOC/THS \\
\hline COR & - & + \\
\hline LOE & - & + \\
\hline Standards of IOM & - & + \\
\hline Table for correct BP measurement & - & + \\
\hline BP variability & - & + \\
\hline Diagnostic algorithm & - & + \\
\hline Treatment algorithm & + & + \\
\hline Adjustment algorithm & - & + \\
\hline \multicolumn{3}{|l|}{ BP targets, $\mathrm{mm} \mathrm{Hg}$} \\
\hline$<130 / 80$ & $\begin{array}{l}\text { Diabetes, CHD and CHD equivalents, } \\
\text { CKD, stroke }\end{array}$ & $\begin{array}{l}\text { Diabetes, CHD, proteinuric CKD, } \\
\text { antithrombotic therapy }\end{array}$ \\
\hline$<140 / 90$ & Primary prevention & Primary prevention, CKD, stroke \\
\hline$<150 / 90$ & Very elderly (>80 years) & Very elderly ( $>80$ years) \\
\hline \multicolumn{3}{|l|}{ Lifestyle modification } \\
\hline S-ABCDE & + & + \\
\hline$\underline{\mathrm{S}}$ & Salt restriction $<6.0 \mathrm{~g} /$ day & Sodium restriction $2.0-4.0 \mathrm{~g} /$ day \\
\hline Body weight reduction & BMI $18.5-24.9$ & BMI $22.5-25.0$ \\
\hline Exercise adoption (aerobic) & $30 \mathrm{~min} /$ day, at least 5 days/week & $40 \mathrm{~min} /$ day, at least $3-4$ days/week \\
\hline List of recommended drugs & + & + \\
\hline List of recommended combinations & + & - \\
\hline Figure for 'Rule of 10' & - & + \\
\hline Figure for 'Rule of 5' & - & + \\
\hline Nonpharmacological therapy & - & + \\
\hline Renal nerve denervation & - & + \\
\hline Perioperative management & - & + \\
\hline
\end{tabular}

Adapted from the 2015 TSOC/TSH hypertension guideline [4] with permission. CKD = Chronic kidney disease; IOM = Institute of Medicine.

in addition to the treatment algorithm, PROCEED (Previous experience, Risk factors, Organ damage, Contraindications or unfavorable conditions, Expert's or doctor's judgment, Expenses or cost, and Delivery and compliance issue), and a novel adjustment algorithm, AT GOALs, were proposed to guide the process of medication change (fig. 1). 
Cheng et al:: The Novelty of the 2015 Guidelines of the Taiwan Society of Cardiology and the Taiwan Hypertension Society for the Management of Hypertension

Fig. 1. Adjustment algorithm adapted from the 2015 TSOC/ TSH hypertension guidelines [4] with permission.

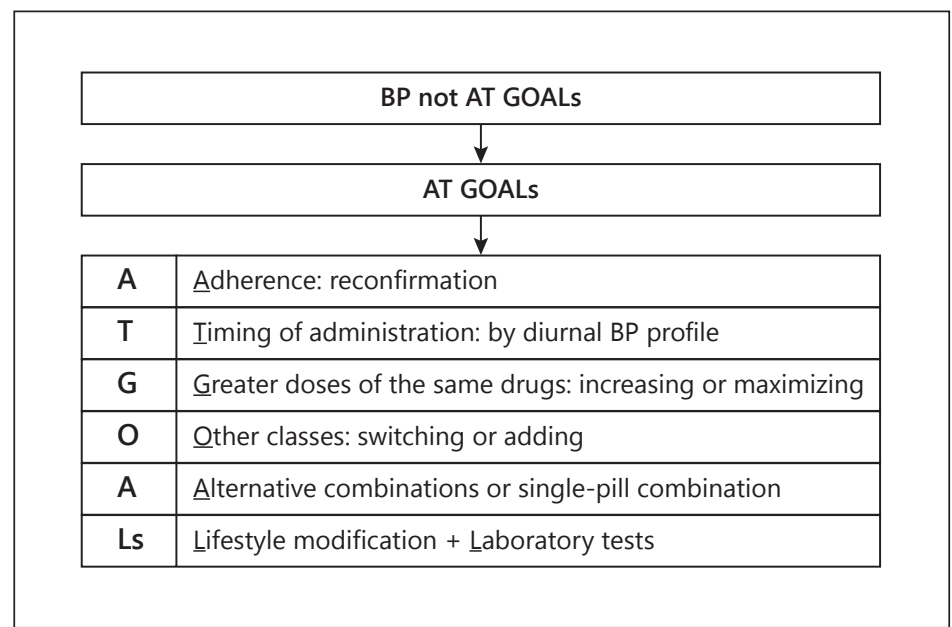

\section{What Is Unique in the 2015 TSOC/THS Hypertension Guideline?}

In this updated guideline, the effort of translating the concept of central BP into clinical practice may stand out from all other hypertension guidelines.

With sustained hypertension, the central organs - the heart, brain and kidneys - are exposed to the pulsatile damage. All the traditional ways of measuring BP, including office BP measurement, home BPM, and ambulatory BPM, use the recordings from brachial arteries, which may be very different from central BP measured in the ascending aorta or carotid arteries, where these central organs are directly exposed to. This well-ascertained phenomenon, the BP amplification from the central aorta to peripheral arteries [9], has raised considerable research interest in the prognostic and diagnostic value of central BP [10]. During hemodynamic changes or after pharmacological interventions, such individual discrepancies between central BP and peripheral BP may be highly variable and cannot be ignored [11]. In this regard, BP measurements in the peripheral arteries may not be a good surrogate for their central counterpart [12]. Using an outcome-driven approach to examine the discriminatory ability of central BP for long-term cardiovascular outcomes [13], an operational threshold for central BP, 130/90 mm Hg, has been derived and validated in two independent Taiwanese cohorts $[14,15]$. This central BP cutoff value has a greater discriminatory power for long-term events [13] and may have a higher sensitivity and a more negative predictive value than peripheral BP in the diagnosis of hypertension [16], subsequently rendering the application of central BP in clinical practice a more cost-effective approach [17].

In the 2015 TSOC/THS hypertension guideline, the measurement of central BP with a cutoff value of $130 / 90 \mathrm{~mm} \mathrm{Hg}$ is recommended when a diagnosis of hypertension is clinically suspected but cannot be established by current conventional BP criteria (COR: IIb; LOE: B).

\section{Conclusion}

In a transparent and rigorous guideline development process, the most updated information available in the management of hypertension was summarized in 2015 TSOC/TSH hypertension guideline. This guideline may deliver useful information and guidance to clinicians in managing hypertensive patients, especially in Asian countries, including the approach to a more accurate diagnosis, treatment and adjustment algorithm, and evidence-based recommendations. 
Cheng et al.: The Novelty of the 2015 Guidelines of the Taiwan Society of Cardiology and the Taiwan Hypertension Society for the Management of Hypertension

\section{Disclosure Statement}

The authors have no conflicts of interest to declare.

\section{References}

1 Chiang CE, Wang TD, Li YH, Lin TH, Chien KL, Yeh HI, Shyu KG, Tsai WC, Chao TH, Hwang JJ, Chiang FT, Chen JH: 2010 guidelines of the Taiwan Society of Cardiology for the management of hypertension. J Formos Med Assoc 2010;109:740-773.

2 James PA, Oparil S, Carter BL, Cushman WC, Dennison-Himmelfarb C, Handler J, Lackland DT, LeFevre ML, MacKenzie TD, Ogedegbe O, Smith SC Jr, Svetkey LP, Taler SJ, Townsend RR, Wright JT Jr, Narva AS, Ortiz E: 2014 evidence-based guideline for the management of high blood pressure in adults: report from the panel members appointed to the Eighth Joint National Committee (JNC 8). JAMA 2014;311:507-520.

3 Task Force Members: 2013 ESH/ESC guidelines for the management of arterial hypertension: the Task Force for the Management of Arterial Hypertension of the European Society of Hypertension (ESH) and of the European Society of Cardiology (ESC). Eur Heart J 2013;34:2159-2219.

4 Chiang CE, Wang TD, Ueng KC, Lin TH, Yeh HI, Chen CY, Wu YJ, Tsai WC, Chao TH, Chen CH, Chu PH, Chao CL, Liu PY, Sung SH, Cheng HM, Wang KL, Li YH, Chiang FT, Chen JH, Chen WJ, Yeh SJ, Lin SJ: 2015 Guidelines of the Taiwan Society of Cardiology and the Taiwan Hypertension Society for the Management of Hypertension. J Chin Med Assoc 2015;78:1-47.

5 Su TC, Bai CH, Chang HY, You SL, Chien KL, Chen MF, Chen HJ, Pan WH, Tseng CH, Cheng SH, Hurng BS, Hwang LC, Chen CJ: Evidence for improved control of hypertension in Taiwan: 1993-2002. J Hypertens 2008;26: 600-606.

6 Ueshima H, Sekikawa A, Miura K, Turin TC, Takashima N, Kita Y, Watanabe M, Kadota A, Okuda N, Kadowaki T, Nakamura Y, Okamura T: Cardiovascular disease and risk factors in Asia: a selected review. Circulation 2008;118:2702-2709.

7 O’Donnell MJ, Xavier D, Liu L, Zhang H, Chin SL, Rao-Melacini P, Rangarajan S, Islam S, Pais P, McQueen MJ, Mondo C, Damasceno A, Lopez-Jaramillo P, Hankey GJ, Dans AL, Yusoff K, Truelsen T, Diener HC, Sacco RL, Ryglewicz D, Czlonkowska A, Weimar C, Wang X, Yusuf S; INTERSTROKE Investigators: Risk factors for ischaemic and intracerebral haemorrhagic stroke in 22 countries (the INTERSTROKE study): a case-control study. Lancet 2010;376:112-123.

8 Martiniuk AL, Lee CM, Lawes CM, Ueshima H, Suh I, Lam TH, Gu D, Feigin V, Jamrozik K, Ohkubo T, Woodward M; Asia-Pacific Cohort Studies Collaboration: Hypertension: its prevalence and population-attributable fraction for mortality from cardiovascular disease in the Asia-Pacific region. J Hypertens 2007;25:73-79.

9 Karamanoglu M, O’Rourke MF, Avolio AP, Kelly RP: An analysis of the relationship between central aortic and peripheral upper limb pressure waves in man. Eur Heart J 1993;14:160-167.

10 Sharman JE, Laurent S: Central blood pressure in the management of hypertension: soon reaching the goal? J Hum Hypertens 2013;27:405-411.

11 Williams B, Lacy PS, Thom SM, Cruickshank K, Stanton A, Collier D, Hughes AD, Thurston H, O’Rourke M: Differential impact of blood pressure-lowering drugs on central aortic pressure and clinical outcomes: principal results of the Conduit Artery Function Evaluation (CAFE) study. Circulation 2006;113:1213-1225.

12 Agabiti-Rosei E, Mancia G, O’Rourke MF, Roman MJ, Safar ME, Smulyan H, Wang JG, Wilkinson IB, Williams B, Vlachopoulos C: Central blood pressure measurements and antihypertensive therapy: a consensus document. Hypertension 2007;50:154-160.

13 Cheng HM, Chuang SY, Sung SH, Yu WC, Pearson A, Lakatta EG, Pan WH, Chen CH: Derivation and validation of diagnostic thresholds for central blood pressure measurements based on long-term cardiovascular risks. J Am Coll Cardiol 2013;62:1780-1787.

14 Chen CH, Ting CT, Lin SJ, Hsu TL, Ho SJ, Chou P, Chang MS, O'Connor F, Spurgeon H, Lakatta E, Yin FC: Which arterial and cardiac parameters best predict left ventricular mass? Circulation 1998;98:422-428.

15 Chuang SY, Bai CH, Chen WH, Lien LM, Pan WH: Fibrinogen independently predicts the development of ischemic stroke in a Taiwanese population: CVDFACTS study. Stroke 2009;40:1578-1584.

16 Cheng HM, Sung SH, Chuang SY, Pearson A, Tufanaru C, White S, Yu WC, Chen CH: Diagnostic performance of a stand-alone central blood pressure monitor: application of central blood pressure in the diagnosis of high blood pressure. Am J Hypertens 2014;27:382-391.

17 Cheng HM, Pearson A, Sung SH, Yu WC, Chen CH, Karnon J: Cost-Effectiveness of Noninvasive Central Blood Pressure Monitoring in the Diagnosis of Hypertension. Am J Hypertens 2015;28:604-614. 